\title{
The Crisis in Creativity Research Stems From Too Little Fragmentation, Not Too Much
}

\author{
John Baer \\ Rider University Lawrenceville, USA \\ E-mail address: baer@rider.edu
}

\section{ARTICLE INFO}

\section{Keywords:}

Fragmentation

Domain-specificity

\section{Article history:}

Received 25 September 2014

Received in revised form 18 December 2014

Accepted 21 December 2014

ISSN: 2354-0036

DOI: 10.15290/ctra.2014.01.02.04

\section{A B STRACT}

Glăveanu is right that there is a crisis in creativity research, but his prescription would make things worse, not better. It is the attempt to build grand, domain-transcending, allencompassing theories that has crippled creativity research and led to a field in which it is the norm for research results to contradict each other. Creativity is more like expertise (where every domain has its own definition and understanding of what constitutes expertise) than intelligence (where $g$ reigns, albeit not without critics). The skills, traits, and motivations that lead to creative performance in physics, poetry, and painting are not fungible: one's intrinsic motivation to write poetry cannot be transmuted into a love of painting, one's openness to experience in art does not make one more open to new ideas in physics, and one's physicsrelated divergent-thinking skill will not lead to more creative poems. Intrinsic motivation, openness to experience, and divergent thinking may promote creativity in many (but probably not all) domains, but they are different in each domain, as will be their effects. Treating them as domain-general skills or attributes invites confusion. We need more fragmentation, in the sense of more domain-specific theories, if we want to make progress in understanding creativity.

Glăveanu's (2014) paper, "The Psychology of Creativity: A Critical Reading," is very interesting, and there are many areas in which I find myself in agreement with his analysis:

"the psychology of creativity is close to a crisis" (Glăveanu, 2014, p. 10)

"the definition and assessment of creativity have long been a subject of disagreement and dissatisfaction among psychologists" (Glăveanu, 2014, p. 14)

"The whole edifice of psychometric creativity testing. . . is mainly built around divergent thinking tasks ... We can legitimately ask, how is this experiential and ontological richness of creativity as a phenomenon ever contained in tasks like 'please generate as many uses as possible for a brick'?" (Glăveanu, 2014, p. 16)

"Finding the neurological correlates of creativity is a current fascination, but what this 
really tells us (or can legitimately tell us) about creativity escapes many researchers engaged in this area of investigation" (Glăveanu, 2014, p. 13)

"most of the assumptions underpinning the [creativity] research remain unfortunately unquestioned" (Glăveanu, 2014, p. 14)

"Corporate training is full nowadays of pseudo-scientific conclusions and tricks of the trade coming from supposed creativity studies. Their main fault . . . is the implicit assumption that one size fits all and that what works within one context will probably work in another" (Glăveanu, 2014, p. 25).

It is on the first of these claims - that the psychology of creativity is in crisis - that I will focus, both because this is his central claim and because I believe his analysis misses the most important explanation for this crisis. Like Glăveanu, I believe recognizing this crisis is essential if creativity research is to make progress. Unlike Glăveanu, I don't think that "fragmentation and dispersion" (Glăveanu, 2014, p. 10) are problematic or that "one of the most problematic aspects faced by the psychology of creativity today [is] an increasing accumulation of research findings without being matched by theorybuilding" (Glăveanu, 2014, p. 22). I think fragmentation and dispersion are the direction creativity research must go if it is to make any progress at all, and I believe there are far too many grand theories of creativity already.

Abstract concepts (like creativity) bring together things that are similar. Some concepts bring together things that are all quite similar in many respects, whereas other concepts bring together things for which it is difficult to identify a single feature that all members of the group share. For example, the concept "billiards" brings together a group of closely related things. "Sports" share many similarities but are a more diverse group, making it harder to identify the shared features of all the things we call sports. "Games" are trickier still; as Wittgenstein (1953/2001) noted, the things we call games may have overlapping similarities but no single defining feature shared by all.

Studying billiards would be fairly easy. Studying sports would be harder, and studying games as a group would sorely test the creativity of the researcher (and would almost certainly result in a constricted definition that included some but not all games). Definitions are elusive with concepts like sports and perhaps impossible with concepts like games. But to do research, as Glăveanu reminds us, we need definitions. He notes that "offering a clear definition makes one vulnerable to criticism" (Glăveanu, 2014, p. 14), but he is nonetheless correct in insisting that we must have them.

Consider two concepts that are related to creativity: intelligence and expertise. There is dispute about how fully unified the concept of general intelligence may be, but general 
intelligence has been a very productive concept in psychological theory, research, and testing (Neisser et al, 1996). If someone exhibits intelligence in one area, it is very likely that person will exhibit intelligence in other areas to a similar degree. Intelligence is fungible, like money: It can be used profitably in many very different kinds of endeavor.

Expertise is quite different. No one assumes that because someone is an expert in Japanese art that person will also know a great deal about French cuisine, airplane mechanics, or neurosurgery, or that expertise is readily transferable across domains. There are no tests of general expertise comparable to IQ tests, and although everyone agrees that expertise is important, it is clear that the set of things pulled together by the term "expertise" is a diverse lot indeed, varying greatly by domain - much more like "games" than "billiards." When researchers study expertise it is quite natural to define and study it in terms of domains.

Creativity is more like expertise than intelligence in being very domain specific (Baer, 1993, 2010, 2011, in press). Should we really expect creativity in poetry or dance or painting to predict creativity in engineering or cooking or interpersonal relations? Feist (2004) commented that it is "a very appealing, and ultimately firmly American, notion that a creative person could be creative in any domain he or she chose. All the person would have to do would be to decide where to apply her or his talents and efforts, practice or train a lot, and voila, you have creative achievement. On this view, talent trumps domain and it really is somewhat arbitrary in which domain the creative achievement is expressed." Although appealing, Feist concluded that "this is a rather naïve and ultimately false position and that creative talent is in fact domain specific . . creativity and talent are usually not among the domain general skills" (Glăveanu, 2014, p. 57).

Domain specificity has huge implications for creativity theory and research. Rather than look for the kinds of grand theories that might be appropriate for a concept like intelligence, creativity researchers need to look at creativity domain by domain, as one must do with expertise. Glăveanu complained that "Scholars seem to have abandoned the 'big' questions in favour of increasingly specialised inquiries leading them to develop subfields of a subfield" (Glăveanu, 2014, p. 12), but the only way to make progress when dealing with a domain-specific concept like creativity is to think small. Glăveanu argued that "most of the assumptions underpinning the research remain unfortunately unquestioned' (Glăveanu, 2014, p. 14). I believe this is also the key flaw in his analysis: He has failed to question the assumption of domain generality that has plagued creativity research and is the reason the literature is littered with conflicting results and contradicting measures of creativity. (Want a different result? Simply use a different test of creativity.) 
Glăveanu wrote that "we need to acknowledge the importance of 'grand theories' for organising and guiding our research and, most significantly, we need to acknowledge that we are guided by such theories and paradigmatic views even when we think we are not" (Glăveanu, 2014, p. 22). I agree that we need to acknowledge the power that grand theories have over us - including the unfortunate power of the most deceptive idea of all, the assumption that a grand theory is even possible in creativity. These ideas do indeed guide us, even when we fail to recognize their influence. But domain specificity has shown that no grand theory can possibly work, so rather than guide, these theories mislead us, pushing us to think of creativity as a much more homogeneous and unified concept than it is. This is the crisis in creativity, and this is why creativity research seems to spin its wheels but go nowhere. As one example of this, consider the longstanding debate about mental illness and creativity, which is as unproductive as it is endless (see, e.g., Bartlett, 2014; Simonton, 2014). As long as creativity researchers insist on thinking of creativity as a domain-general attribute, the debate will never end. As Simonton (2010, pp. 226-228) wrote, "the rate and intensity of adulthood symptoms vary according to the particular domains in which creative genius is expressed. . . geniuses in the natural sciences tend to be more mentally healthy than in the social sciences; geniuses in the social sciences, more so than those in the humanities; and geniuses in the humanities, more so than those in the arts". Looking at the question domain by domain, the question can be answered; looking at it as a creativity-wide question, however, it will never be resolved because it depends on which domains one happens to include in one's sample. (Want a different answer? Simply examine a different domain.)

We need more fragmentation and dispersion - more recognition that creativity in one area may have nothing to do with creativity in other areas - and fewer grand theories of creativity. Glăveanu applauded the Amusement Park Theory of Creativity (Baer \& Kaufman, 2005; Kaufman \& Baer, 2004, 2005), arguing that we "need more initiatives like these if the field is to make a real contribution to scientific debates and practice" (Glăveanu, 2014, p. 24). I agree. The Amusement Park Theory argues that creativity varies across domains in a hierarchical fashion: Creativity in closely related domains will evidence similarities (and the more closely related the domains, the greater such similarities will be), whereas creativity in unrelated domains may be like the elements of the set we call "games," about which we can make no general claims whatsoever.

As Glăveanu proposed, let's “Ask bold, new, and surprising questions” and "Reflect on definitions, do not simply take them for granted" (Glăveanu, 2014, p. 27). But let's ask questions and reflect on definitions that look at creativity as it actually is - very domain 
specific - and not as we might wish it to be (domain general). Then we can make progress - fragmented progress, but real progress — in creativity research. Then we can began to understand why creativity research has produced so many conflicting and contradictory research results, and we can begin to make sense of those diverse findings. Seeking grand theories only leads to illusions and confusion, and to the continuing and long-standing crisis in creativity research of which Glăveanu has reminded us (see, e.g., Glover, Ronning, \& Reynolds, 1989, for similar warnings 25 years ago). As long as we have impossible expectations of creativity theory it will always be in crisis. We can study it, just as we can study expertise, but we need to do so domain by domain. In doing so we may note interesting similarities among some domains, and there will be striking differences as well.

Glăveanu reminds us that Torrance said "creativity is almost infinite" (Glăveanu, 2014, p. 18). We should expect great complexity — and few simple, all encompassing answers - from a concept with such extraordinary reach.

\section{REFERENCES}

Baer, J. (1993). Creativity and divergent thinking: A task-specific approach. Hillsdale, NJ: Lawrence Erlbaum Associates.

Baer, J. (2010). Is creativity domain specific? In J.C. Kaufman \& R.J. Sternberg (Eds.), Cambridge handbook of creativity (pp. 321-341). Cambridge University Press.

Baer, J. (2011). Why grand theories of creativity distort, distract, and disappoint. International Journal of Creativity and Problem Solving, 21(1). 73-100.

Baer, J. (in press). Domain specificity in creativity. San Diego: Elsevier.

Baer, J. \& Kaufman, J.C. (2005). Bridging generality and specificity: The Amusement Park Theoretical (APT) model of creativity. Roeper Review, 27, 158-163.

Bartlett, T. (2014, September 19). Madness and the muse. The Chronicle of Higher Education. Retrieved September 20, 2014 at http://m.chronicle.com/article/MadnesstheMuse/148845/ .

Feist, G.J. (2004). The evolved fluid specificity of human creative talent. In R.J. Sternberg, E.L. Grigorenko, \& J.L. Singer (Eds.), Creativity: From potential to realization (pp. 57-82). Washington, DC: American Psychological Association.

Glăveanu, V.P. (2014). The psychology of creativity: A critical reading. Creativity: Theories - Research - Applications, 1, 10-32, DOI: 10.15290/ctra.2014.01.01.02.

Glover, J.A., Ronning, R.R., \& Reynolds, C.R. (1989). Handbook of creativity. New York: Plenum Press. 
Kaufman, J.C. \& Baer, J. (2004). The Amusement Park Theoretical (APT) model of creativity. The Korean Journal of Thinking \& Problem Solving, 14(2), 15-25.

Kaufman, J.C. \& Baer, J. (2005). The Amusement Park Theory of creativity. In J.C. Kaufman \& J. Baer (Eds.), Creativity across domains: Faces of the muse (pp. 321-328). Hillsdale, New York: Lawrence Erlbaum Associates.

Neisser, U., Boodoo, G., Bouchard, T.J., Boykin, A.W., Brody, N., Ceci, S.J., Halpern, D.F., Loehlin, J.C., Perloff, R., Sternberg, R.J. \& Urbina, S. (1996). Intelligence: Knowns and unknowns. American Psychologist, 51, 77-101.

Simonton, D.K. (2010). So you want to become a creative genius? You must be crazy! In D. Cropley, J. Kaufmann, A. Cropley, \& M. Runco (Eds.), The dark side of creativity (pp. 218-234). New York: Cambridge University Press.

Simonton, D.K. (2014). More method in the mad-genius controversy: A historiometric study of 204 historic creators. Psychology of Aesthetics, Creativity, and the Arts, 8(1), 53-61.

Wittgenstein, L. (1953/2001). Philosophical investigations. Oxford: Blackwell Publishing.

Corresponding author at: John Baer, Rider University, Memorial Hall 102, Lawrenceville, NJ 08648-3099, USA.

E-mail: baer@rider.edu 